폐닥나무의 입도제어에 따른 흡·방습 특성 분석

\author{
조기식* · 김태연* · 서성관* - 이오규** . 추용식* \\ *한국세라믹기술원 에너지환경본부, **국립산림과학원 산림바이오소재연구소
}

\title{
Analysis for Water Vapour Adsorption and Desorption Performance of Waste Paper-Mulberry according to Particle Size Control
}

\author{
Ki-Sic Jo*, Tae-Yeon Kim*, Sung-Kwan Seo*, Oh-Kyu Lee** and ${ }^{\S}$ Yong-Sik Chu* \\ *Energy \& Environmental Division, Korea Institute of Ceramic Eng. \& Tech., Jinju 52851, Korea \\ **Forest Biomaterials Research Center, National Institute of Forest Science
}

\begin{abstract}
요 약
본 연구에서는 분쇄 가공된 폐닥나무의 친환경 조습 제품에 대한 적용 가능성을 확인하기 위해 인피섬유와 폐닥나무 분쇄 펠렛의 흡. 방습 성능 측정을 진행하였다. 폐닥나무 분말은 710-355 $\mu \mathrm{m}, 355-100 \mu \mathrm{m}, 100-45 \mu \mathrm{m}$ 및 $45 \mu \mathrm{m}$ 미만의 입도별로 분류하여 사용하였다. 분말 의 비표면적은 입자 크기가 $710 \mu \mathrm{m} ㅂ ㅜ ㅌ ㅓ ~ 45 \mu \mathrm{m}$ 미만으로 감소할수록 $1.02 \mathrm{~m}^{2} / \mathrm{g}$ 에서 $1.35 \mathrm{~m}^{2} / \mathrm{g}$ 로 증가하는 경향을 나타내었다. 흡. 방습량은 $355-100 \mu \mathrm{m}, 710-355 \mu \mathrm{m}, 100-45 \mu \mathrm{m}, 45 \mu \mathrm{m}$ 미만 및 인피섬유의 순으로 감소하였으며, 각각 $141.1 \mathrm{~g} / \mathrm{m}^{2}, 147.1 \mathrm{~g} / \mathrm{m}^{2}, 135.7 \mathrm{~g} / \mathrm{m}^{2}, 129 \mathrm{~g} / \mathrm{m}^{2}$ 의 흡 습 및 $117.2 \mathrm{~g} / \mathrm{m}^{2}, 123.6 \mathrm{~g} / \mathrm{m}^{2}, 110.2 \mathrm{~g} / \mathrm{m}^{2}, 93.3 \mathrm{~g} / \mathrm{m}^{2}$ 의 방습 성능이 확인되었다. 폐닥나무 분말의 흡습 및 방습 성능은 닥나무 인피섬유 보 다 우수하였으며, 이는 펠렛 내부 기공의 분포와 섬유 손상에 기인한 것으로 사료되었다.
\end{abstract}

주제어 : 닥나무, 인피섬유, 분말, 친환경, 조습

\begin{abstract}
In this study, adsorption and desorption characteristics of pulverized waste paper-mulberry pellet and bast fiber were measured to confirm the applicability to humidity control products. Paper-mulberry powder was classified by $710-355 \mu \mathrm{m}$, $355-100 \mu \mathrm{m}, 100-45 \mu \mathrm{m}$ and less than $45 \mu \mathrm{m}$ and used in experiment. Specific surface area increased from $1.02 \mathrm{~m}^{2} / \mathrm{g}$ to $1.35 \mathrm{~m}^{2} / \mathrm{g}$ as the particle size decreased from $710 \mu \mathrm{m}$ to under $45 \mu \mathrm{m}$. Adsorption and desorption performance decreased in the order of $355-100$ $\mu \mathrm{m}, 710-355 \mu \mathrm{m}, 100-45 \mu \mathrm{m}$, less than $45 \mu \mathrm{m}$ and bast fiber, adsorption content on each particle sizes were $141.1 \mathrm{~g} / \mathrm{m}^{2}, 147.1 \mathrm{~g} / \mathrm{m}^{2}$, $135.7 \mathrm{~g} / \mathrm{m}^{2}, 129.0 \mathrm{~g} / \mathrm{m}^{2}$ and desorption content were $117.2 \mathrm{~g} / \mathrm{m}^{2}, 123.6 \mathrm{~g} / \mathrm{m}^{2}, 110.2 \mathrm{~g} / \mathrm{m}^{2}, 93.3 \mathrm{~g} / \mathrm{m}^{2}$. As a result, adsorption and desorption performance of paper-mulberry powder were superior to those of the bast fiber and these phenomenon can be considered that it caused by pore distribution in pellet and damage of fiber.
\end{abstract}

Key words : paper-mulberry, bast fiber, powder, eco-friendly, humidity self-control

\footnotetext{
$\cdot$ Received : January 30, 2020 · Revised : March 16, $2020 \cdot$ Accepted : March 23, 2020

$\S$ Corresponding Author : Yong-Sik Chu (E-mail : yschu@kicet.re.kr)

Energy \& Environmental Division, Korea Institute of Ceramic Engineering \& Technology, 101, Soho-ro, Jinju-si, Gyeongsangnamdo 52851, Korea

(C) The Korean Institute of Resources Recycling. All rights reserved. This is an open-access article distributed under the terms of the Creative Commons Attribution Non-Commercial License (http://creativecommons.org/licenses/by-nc/3.0/), which permits unrestricted non-commercial use, distribution and reproduction in any medium, provided the original work is properly cited.
} 


\section{1. 서 론}

국민소득 수준 향상에 따라 새집 증후군, 유해물질 저 감 등 실내 공기길 개선에 대한 관심이 증가하고 있다. 특 히 하루 중 $80-90 \%$ 이상을 실내에서 생활하는 현대인들 은 아토피나 알레르기 비염, 천식 등의 증가에 따라 건강 을 위한 친환경 주거공간을 구축하려는 심리가 계속 증가 하고 있으며, 이에 대한 법적 규제도 점차 강화되는 추세 이다 ${ }^{1-2)}$.

건강을 위한 주거공간의 주요 요인 중 하나로 실내 습도 조건이 대두되고 있으며, 여러 연구결과에 따르면 40-70\% 의 습도 범위가 가장 적절하다고 발표되고 있다. 습도가 높 은 환경에서는 곰팡이와 세균 등의 증식과 천식, 알레르기 및 비염 증상이 유발되며, 습도가 낮으면 호흡기 질환 및 바이러스의 생존 기간 연장으로 인체에 악영향을 끼친다. 더불어 정전기 축적으로 정밀기기의 오작동, 발화 및 미술 품 등의 열화로 재산피해까지 발생하게 된다. 이에 따라 실 내 적정 습도를 유지하기 위해서 제습기나 가습기의 사용 이 필요하나, 에너지 소비가 크고 장기간 사용 시 기기 내 부에 곰팡이와 진드기 및 각종 세균이 번식하여 오히려 인 체 건강을 해치게 된다 ${ }^{2-4)}$. 따라서 해당 기기의 도움 없이 적정 습도를 유지할 수 있는 친환경적인 방법에 대한 필요 성이 증대되고 있다. 또한, 국내에서는 추 등의 다공성 재 료가 적용된 패널의 조습 특성에 대한 연구 ${ }^{3)}$ 및 해외에서 는 Dinh-Hieu $\mathrm{Vu}$ 등의 폐기물을 활용한 다공성 세라믹의 조습 특성 연구 ${ }^{5)}$ 등이 꾸준히 수행되고 있는 실정이다.

한편, 적정 습도를 자율제어하기 위해 사용되는 조습 재료는 모세관 기공 등에 의해 습도 제어가 가능하다. 이 는 수증기가 응축·액화 또는 응축수 증발을 통해 일정 범 위의 습도를 유지시켜 주는 역할을 하기 때문이다 ${ }^{6}$. 닥나 무 섬유 또한 조습 재료 중의 하나로, 껍질과 목질부 사이 에서 추출 가능하며, 온도와 습도를 자연적으로 조절할 수 있는 기능성과 신축성을 가지고 있다. 더불어 미세 기 공을 통한 환기가 가능하게 하여), 이를 활용한 다양한 연 구· 개발이 활발히 진행되고 있다.

본 연구에서는 품질이 불량하거나 제품 제조에 사용이 어려운 폐닥나무의 가공을 통해 조습 제품에 대한 적용 가 능성을 확인하고자 하였으며, 이를 위해 폐닥나무 섬유 및 섬유를 분말 형태로 제조하여 조습 특성을 비교·분석 하였다.

\section{2. 실험 방법}

흡. 방습 특성 분석은 Fig. 1 의 과정에 따라 진행하였 다. 먼저 가공에 따른 인피섬유의 흡·방습 특성을 분석 하기 위해 폐닥나무에서 추출한 섬유 및 분쇄 분말을 사 용하였으며, Fig. 2에 해당 재료를 나타내었다. 사용된 인 피섬유는 자연 건조를 통해 수축이 이루어진 상태로 사 용하였다. 분말은 건조 섬유를 진동 분쇄기(Analysette3, FRITSCH社, Germany)로 6시간 동안 분쇄한 후 체를 사 용하여 분리하였으며, $710-355 \mu \mathrm{m}, 355-100 \mu \mathrm{m}, 100-45 \mu \mathrm{m}$ 및 $45 \mu \mathrm{m}$ 미만으로 분류하였다. 이 때 진동 분쇄를 6 시간 이하로 진행할 경우 분말 생성이 불가능하였으며, 분말 형태의 확인과 분류 및 획득을 위한 분쇄시간을 최소 6시 간으로 판단하였다.

분쇄 분말은 결정상 분석을 위해 분리하지 않은 상태로 XRD (DMAX 2500, Rigaku社, Japan) 분석을 시행하였 다. 또한, 제작된 펠렛의 흡. 방습 능력과 입도별 분말의 비 표면적간 상관관계를 확인하기 위하여 BET (ASAP2420, Micromeritics社, USA) 분석을 진행하였다. 이후 원형 몰 드에 분말 $3 \mathrm{~g}$ 을 장입한 후 1 분간 4 톤의 압력으로 일축 가 압하여 Fig. 3 과 같은 펠렛(지름 $20 \mathrm{~mm}$, 두께 $7.5 \mathrm{~mm}$ )을 제작하였다. 더불어 폐닥나무 섬유 분쇄 전·후 및 펠렛의 미세구조 특성 분석을 위해 각각의 미세구조를 관찰하였 다(SEM, JSM-6380, JEOL社, Japan). 이때 펠렛 내 잔여

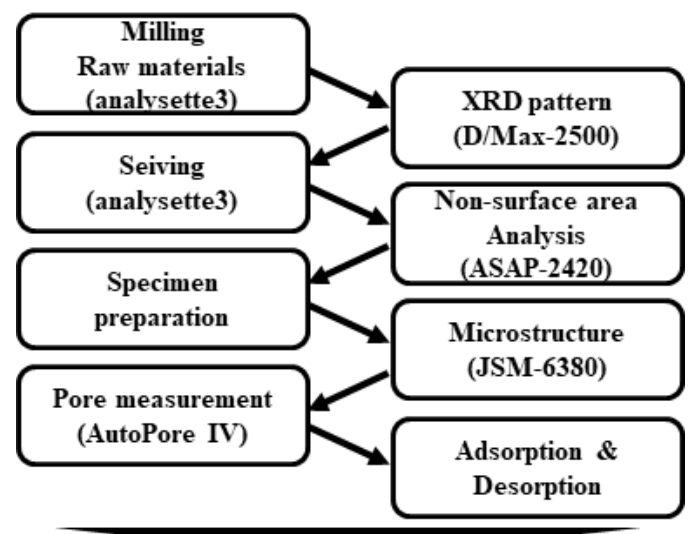

Analysis for Water Vapour Adsorption and Desorption Performance of Waste Paper-Mulberry according to Particle Size Control

Fig. 1. Scheme of experimental flow chart. 


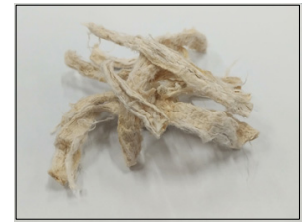

(a) Bast fiber

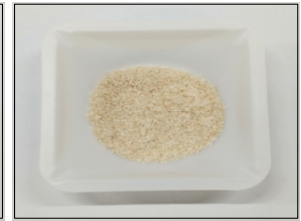

(b) $710-355 \mu \mathrm{m}$

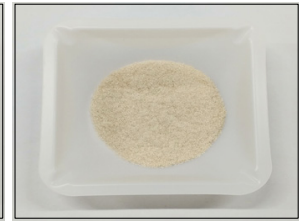

(c) $355-100 \mu \mathrm{m}$

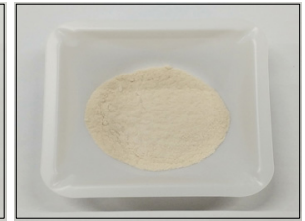

(d) $100-45 \mu \mathrm{m}$

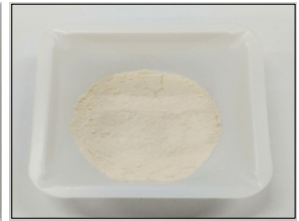

(e) under $45 \mu \mathrm{m}$

Fig. 2. Bast fiber and powders of each particle size.

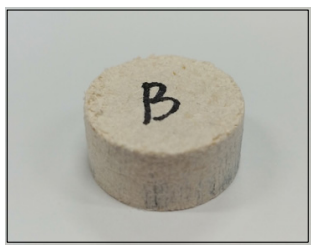

(a) $710-355 \mu \mathrm{m}$

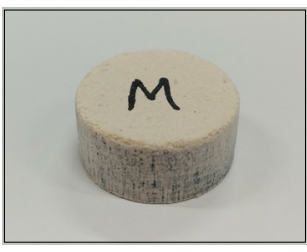

(b) $355-100 \mu \mathrm{m}$

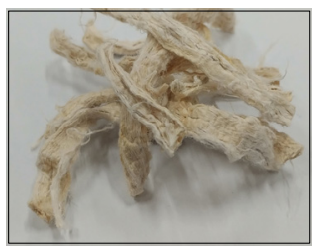

(c) $100-45 \mu \mathrm{m}$

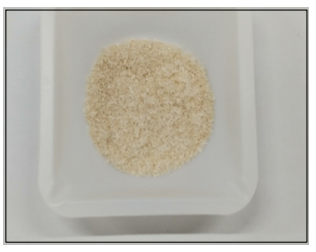

(d) under $45 \mu \mathrm{m}$

Fig. 3. Pellet as each particle size.
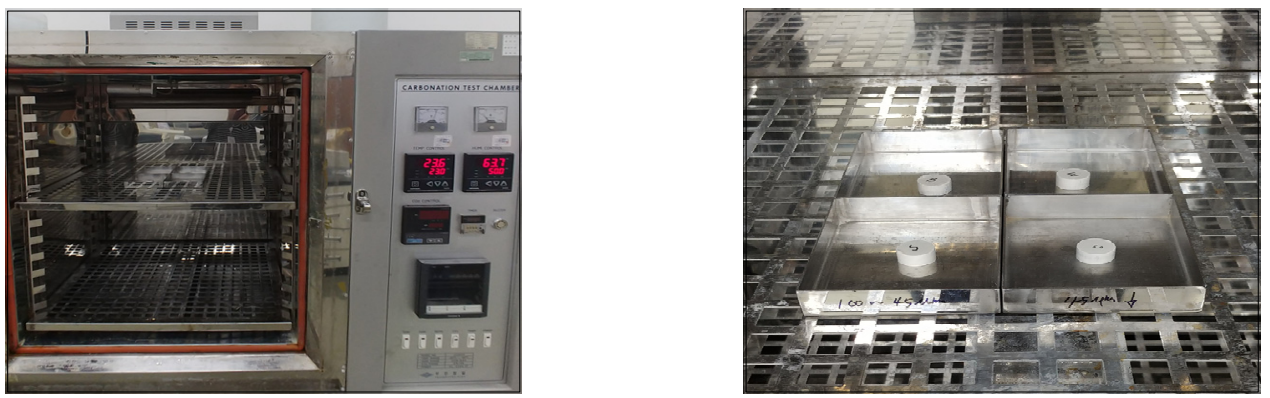

Fig. 4. Water vapor adsorption \& desorption of pellet.

수분을 제거하기 위해 6시간씩 건조하였으며, 수축현상 및 열손상 방지를 위해 온도를 $60^{\circ} \mathrm{C}$ 로 고정하였다. 또한 입자 크기에 따른 기공률을 확인하기 위해 Porosimeter(Auto Pore IV, Micromeritics社, USA)를 활용하여 기공률을 측 정하였다.

조습 특성은 JIS A 1470-1을 준용하여 펠렛과 분쇄하 지 않은 폐닥나무 $($ 약 $5 \mathrm{~g})$ 의 흡 · 방습량을 측정하였다. 일 정한 온 · 습도 조건을 유지하기 위해 Fig. 4와 같이 항온 . 항습기(CC600, 우진정밀社, Korea)를 사용하였으며, 미세 저울(HS 224S, HANSUNG Instrument Co. LTd., Korea) 을 사용하여 2 시간마다 질량 변화를 기록하였다. 시험체 의 안정화를 위해 $50 \% \mathrm{RH}$, 온도 $23 \pm 0.5^{\circ} \mathrm{C}$ 에서 24 시간 동 안 유지시킨 후 흡습( $75 \% \mathrm{RH}-12 \mathrm{hr})$ 및 방습( $50 \% \mathrm{RH}-12 \mathrm{hr})$ 과정을 진행하였으며, 항온항습기 내부 온도는 $23 \pm 0.5^{\circ} \mathrm{C}$ 로 고정하였당.

\section{3. 실험결과}

\section{1. 원료 특성 분석}

Fig. 5(a)는 폐닥나무 껍질과 목질부 사이에서 추출한 인피섬유에 대한 XRD Pattern 분석 결과를 나타낸 것이 다. $15^{\circ}$ 와 $22^{\circ}$ 위치에서 셀룰로오스 피크를 확인 할 수 있 었으며, $38^{\circ}, 44^{\circ}$ 및 $64^{\circ}$ 에서도 피크가 검출되었다. 셀룰 로오스는 바이오매스로부터 얻을 수 있는 가장 풍부한 고 분자 물질로 기계적 특성이 우수하며, 가벼운 무게 및 생 분해성 등 다양한 장점을 보유하고 있어 여러 분야에서 활 용되고 있다 ${ }^{9)}$. 최근 세계적으로 환경 문제가 대두되고 석 유 기반의 합성 고분자 물질을 천연자원으로 대체하고자 하는 움직임이 큰 가운데 닥나무 섬유는 목재 섬유보다 우 수한 셀룰로오스 함량 및 결정화도를 보유한 것으로 알려 져 있다. 더불어 부식에 대한 저항성이 우수하여 여러 산 


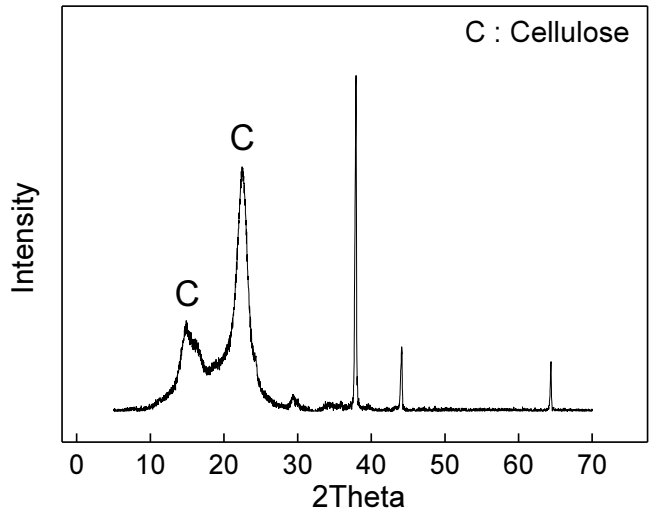

(a) Paper-mulberry

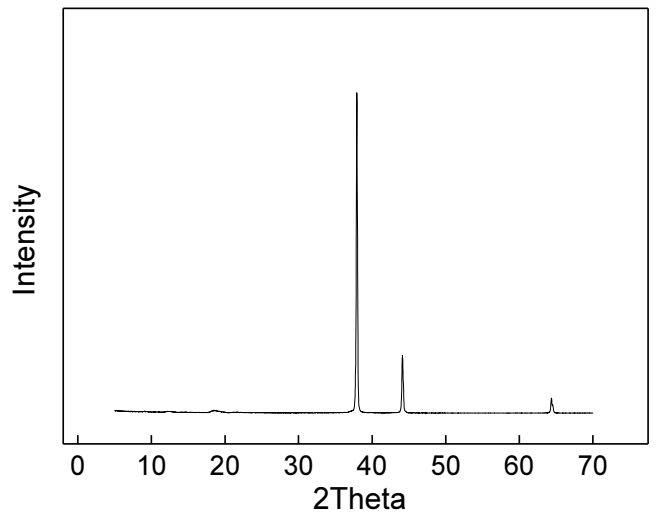

(b) XRD holder

Fig. 5. XRD patterns of bast fiber \& XRD holder.

Table 1. Particle size of ground waste paper-mulberry

\begin{tabular}{|c|c|c|c|c|c|}
\hline Particle size $(\mu \mathrm{m})$ & over 710 & $710-355$ & $355-100$ & $100-45$ & under 45 \\
\hline Content $(\%)$ & 28.69 & 12.03 & 3.75 & 24.99 & 30.54 \\
\hline
\end{tabular}

Table 2. Surface area of each particle size

\begin{tabular}{|c|c|c|c|c|}
\hline Particle size $(\mu \mathrm{m})$ & $710-355$ & $355-100$ & $100-45$ & under 45 \\
\hline Surface $\operatorname{area}\left(\mathrm{m}^{2} / \mathrm{g}\right)$ & 1.02 & 1.11 & 1.23 & 1.35 \\
\hline
\end{tabular}

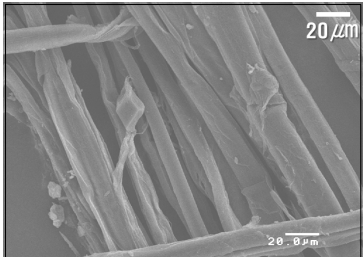

(a) Side X 500

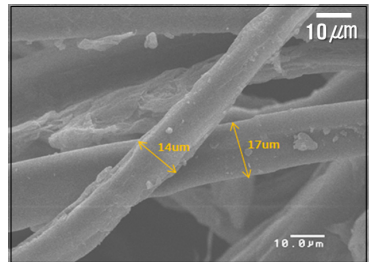

(b) Side X 1000

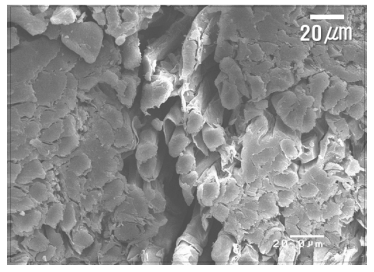

(c) Cross section X 500

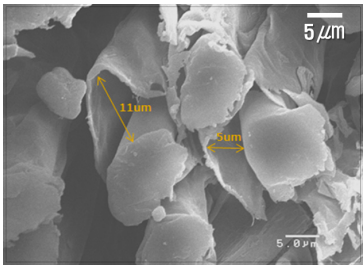

(d) Cross section X 2000

Fig. 6. Microstructure of bast fiber.

업에 이용 가능한 친환경재료 ${ }^{10)}$ 로 판단되었다.

한편, 셀룰로오스 외에 $38^{\circ}, 44^{\circ}$ 및 $64^{\circ}$ 에서 관찰된 피 크는 XRD 홀더 자체를 측정한 결과와 일치하는 것으로 확인되었다. 이와 같은 현상은 X-선이 폐닥나무 분말을 투과하여 XRD 홀더에 부딪친 후 검출되었기 때문으로 사료되었다.

폐닥나무 섬유를 분쇄하여 얻어진 각 분말의 입도별 구 성 비율을 Table 1에 나타내었다. $710 \mu \mathrm{m}$ 초과, $710-355 \mu \mathrm{m}$, $355-100 \mu \mathrm{m}, 100-45 \mu \mathrm{m}$ 및 $45 \mu \mathrm{m}$ 미만의 수준으로 분리하였 으며, $710 \mu \mathrm{m}$ 의 초과분은 실험에 사용하지 않았다. 각 입도 별 구성비는 $28.69 \%, 12.03 \%, 3.75 \%, 24.99 \%, 30.54 \%$ 이
었으며, 이후 각 분말에 대한 비표면적 분석을 진행하였 다. 그 결과, 710-355 $\mu \mathrm{m}, 355-100 \mu \mathrm{m}, 100-45 \mu \mathrm{m}, 45 \mu \mathrm{m}$ 미만 의 순서에 따라 $1.02 \mathrm{~m}^{2} / \mathrm{g}, 1.11 \mathrm{~m}^{2} / \mathrm{g}, 1.23 \mathrm{~m}^{2} / \mathrm{g}$ 및 $1.35 \mathrm{~m}^{2} / \mathrm{g}$ 으로 입자 크기가 감소할수록 비표면적은 늘어나는 일반 적 경향을 확인할 수 있었다(Table 2 참조).

Fig. 6은 폐닥나무 섬유의 미세구조 관찰 결과를 나타 낸 것이다. 여러 줄기의 섬유로 이루어진 다발 형태를 띄

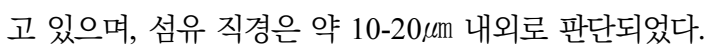
또한, Fig. 6(c)와 (d)에 나타난 단면에서는 닥나무 섬유가 가지는 조습 특성의 주요 요인으로 알려진 관 형태의 기공 이 관찰되었다. 기공의 내강폭은 약 $11 \mu \mathrm{m}$ 까지 관찰되었으 


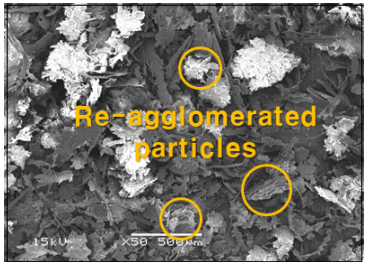

(a) $710-355 \mu \mathrm{m} X 50$

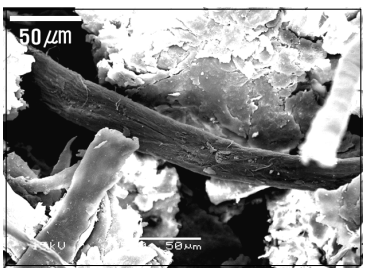

(e) $710-355 \mu \mathrm{m} \times 500$

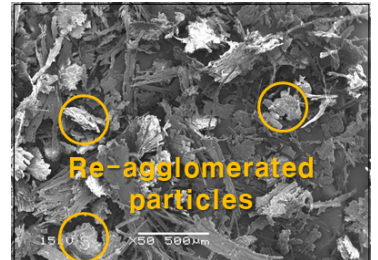

(b) $355-100 \mu \mathrm{m} X 50$

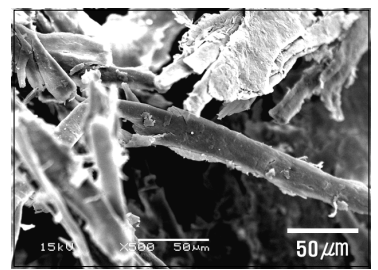

(f) $355-100 \mu \mathrm{m}$ X 500

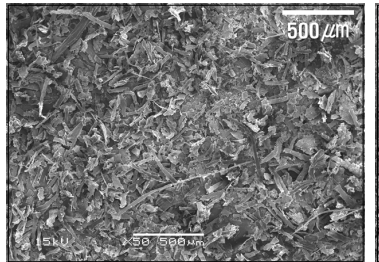

(c) $100-45 \mu \mathrm{m}$ X 50

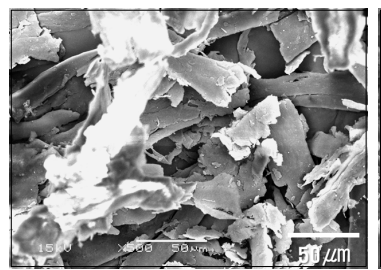

(g) $100-45 \mu \mathrm{m}$ X 500

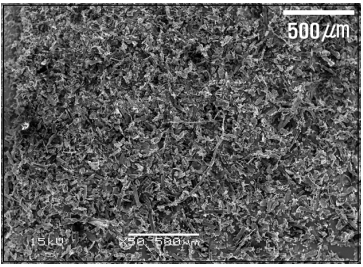

(d) under $45 \mu \mathrm{m}$ X 50

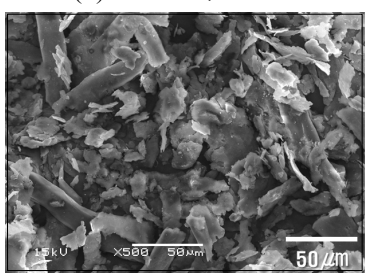

(h) under $45 \mu \mathrm{m}$ X 500

Fig. 7. Microstructure of paepr-mulberry powder.

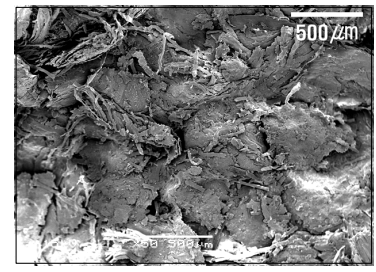

(a) $710-355 \mu \mathrm{m} \times 50$

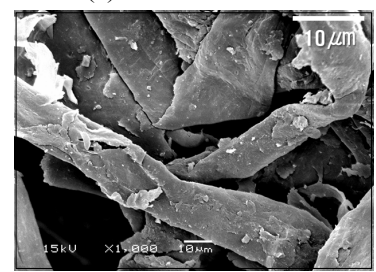

(e) $710-355 \mu \mathrm{m} \mathrm{X} \mathrm{1,000}$

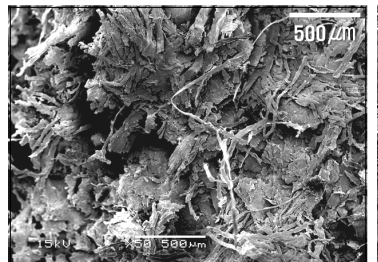

(b) $355-100 \mu \mathrm{m} \mathrm{X} 50$

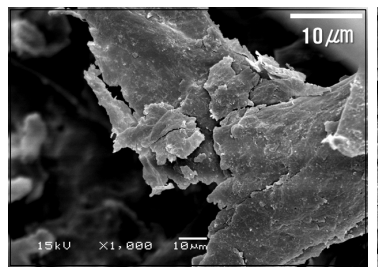

(f) $355-100 \mu \mathrm{m} \mathrm{X} 1,000$

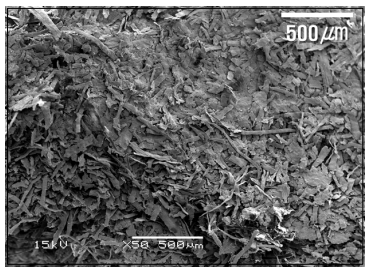

(c) $100-45 \mu \mathrm{m} \times 50$

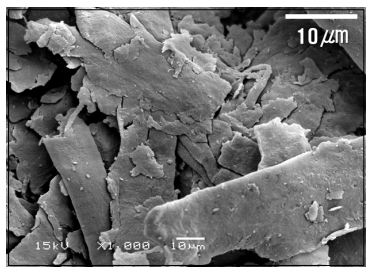

(g) $100-45 \mu \mathrm{m}$ X 1,000

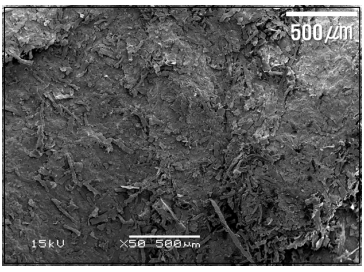

(d) under $45 \mu \mathrm{m}$ X 50

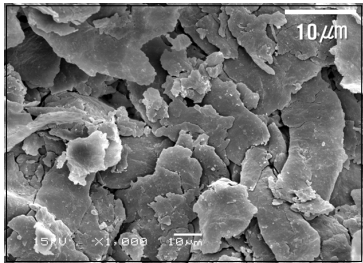

(h) under $45 \mu \mathrm{m}$ X 1,000

Fig. 8. Microstructure on cross section of pellet.

며, 이는 고 등이 연구 발표한 내강폭(4.5-12.5 $\mu \mathrm{m})$ 범위 안 에 있음을 확인하였다 ${ }^{11)}$. 이를 통해 폐닥나무 섬유는 섬유 내부의 관 형태 기공에 의한 흡. 방습 특성을 보유하였을 것으로 사료되었다.

분쇄된 폐닥나무 섬유 분말의 미세구조를 Fig. 7에 나 타내었다. Fig. 7(a)-(d)와 같이, 체분리 입도가 작아질수 록 입자 크기가 작아진다는 것을 확인할 수 있었으며, (e) 와 (f)에서는 완전히 분쇄되지 않고 섬유 상태로 존재하는 형상도 관찰할 수 있었다. Fig. 7(a)와 (b)에서는 대부분 섬유다발의 분리가 발생하지 않았으나, 손상된 섬유 다발 과 분쇄 시 충격에 의해 섬유들이 재응집된 2 차 입자가 관
찰되었다. 반면 Fig. 7(g)와 (h)에서는 섬유다발, 2차 입자 및 비손상 섬유 발견이 어려웠으며, 분리된 섬유가 절단 된 형태의 조각들로 다수 확인되었다.

Fig. 8은 분말로 제조한 펠렛 단면의 미세구조를 나타 낸 것이다. 분말 입자가 작아질수록 섬유 길이 및 다발 밀 집도가 감소하는 경향을 보였으며, 분쇄 공정에서의 충격 으로 인한 손상부위가 확인되었다. 펠렛 단면에서 관찰되 는 기공의 분포는 (b), (a), (c) 및 (d)의 순으로 많았으며, (a)는 섬유다발의 분리가 적게 일어나 비교적 온전한 형태 가 관찰되었다. 반면, (b)에서는 섬유다발의 절단 뿐 아니 라 섬유간의 분리가 일어나 산발적인 형태를 가지는 것으 


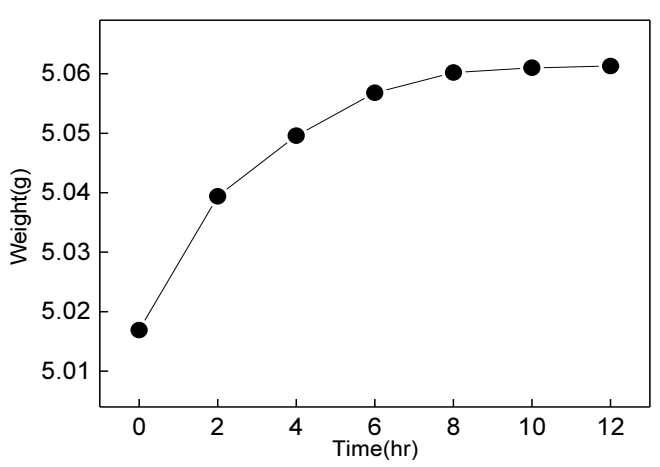

(a) Adsorption of bast fiber

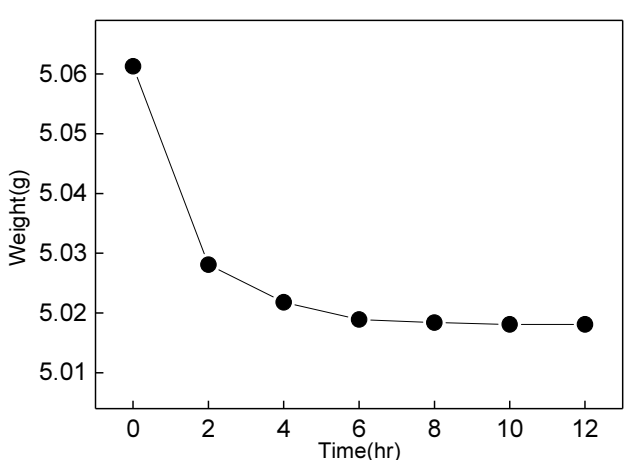

(b) Desorption of bast fiber

Fig. 9. Adsorption and desorption of bast fiber.

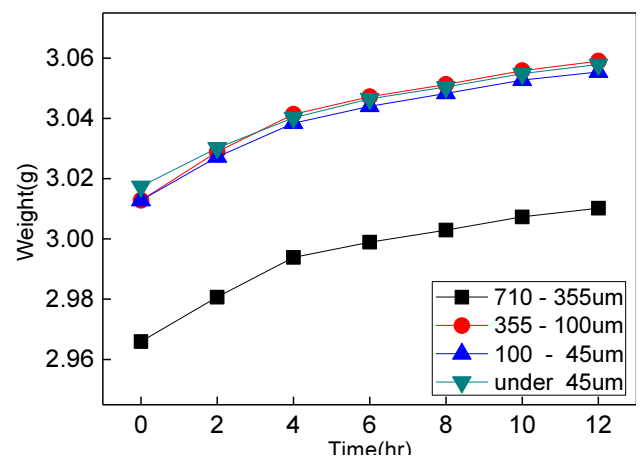

(a) Adsorption of pellet

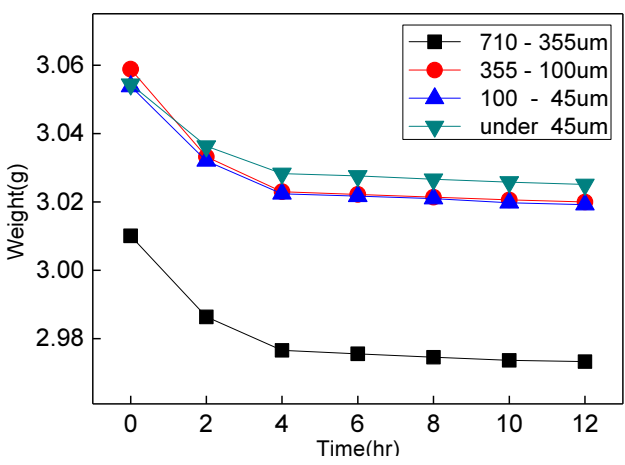

(b) Desorption of pellet

Fig. 10. Adsorption and desorption of pellet.

로 확인되었다. 이러한 형태로 인하여 (a)에서 분말 밀집 이 더 잘 일어나 (b)보다 (a)의 기공 분포가 적은 것으로 판단된다. 또한 Fig. $7(\mathrm{~g})$ 와 $(\mathrm{h})$ 의 얇은 판상 형태의 분말 이 펠렛 성형과정에서 Fig. $8(\mathrm{~g})$ 및 $(\mathrm{h})$ 와 같은 적층 - 압축 되어 기공의 분포가 감소한 것으로 사료된다.

\section{2. 흡·방습 특성 비교}

폐닥나무 섬유와 펠렛의 흡·방습 실험 결과를 Fig. 9 및 Fig. 10 에 나타내었다. 이 때 각 펠렛은 동일한 무게의 분말로 제작하였으나, 탈형 과정에서의 손상과 미세 분말 의 몰드내부 흡착 등으로 인하여 초기 무게의 편차가 발생 하였다. Fig. 9의 폐닥나무 섬유는 4시간 전후까지 흡습량 증가폭이 $0.023 \mathrm{~g}$ 으로 비교적 크게 상승하였으나, 이 후 증가폭이 서서히 감소하는 경향을 나타내었다. 또한 방습 량은 $0-2$ 시간 구간에서 $0.033 \mathrm{~g}$ 수준이었으며, 이후 점차 적으로 완만해지는 경향을 나타내었다. 한편, Fig. 10은
각 입도별 분말로 구성된 펠렛의 흡· 방습에 대한 결과를 그래프로 나타낸 것이다. (a)에서 0-4시간 구간의 펠렛의 흡습량은 분말 입자 크기가 큰 순서에 따라 $0.015 / 0.013 \mathrm{~g}$, $0.016 / 0.013 \mathrm{~g}, 0.014 / 0.011 \mathrm{~g}$ 및 $0.013 / 0.010 \mathrm{~g}$ 수준이었으 며, 이후 구간에서는 점차적으로 흡습량이 감소하며 완만 해지는 경향을 보였다. 또한 (b)에 나타난 방습량은 0-4 시간 구간에서 분말 입자의 크기가 큰 순서에 따라 약 $0.024 / 0.001 \mathrm{~g}, 0.026 / 0.010 \mathrm{~g}, 0.022 / 0.001$ 및 0.018/0.008g 로 무게의 감소폭이 확인되었다. 이후 구간에서는 감소량 의 변화폭이 줄어들었으며, 급격히 완만해지는 것을 확인 할 수 있었다. 이를 통해 각 시험체간 흡습 및 방습 실험에 서의 거동이 유사한 경향을 보이는 것으로 추정되었다.

Fig. 11(a)는 입자 크기에 따른 비표면적 값을 나타낸 그래프이며, 입자 크기가 감소할수록 비표면적이 증가하 는 일반적인 경향을 나타내었다. Fig. 11(b)는 인피섬유와 펠렛의 흡 · 방습율을 나타낸 것이며, 펠렛의 경우 입자 크 


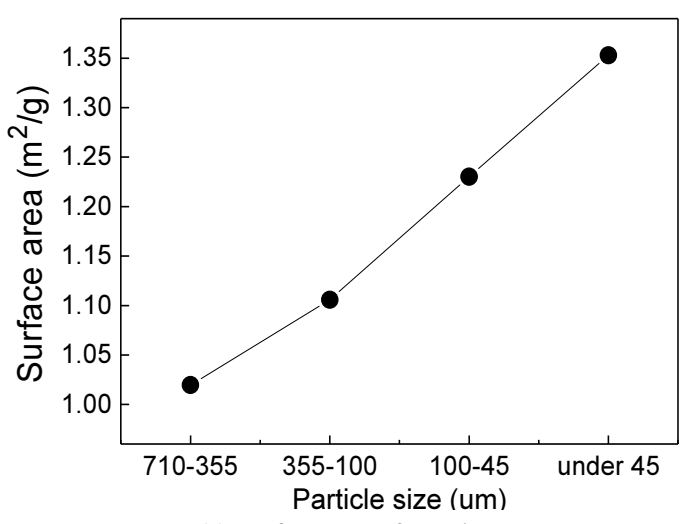

(a) Surface area of powder

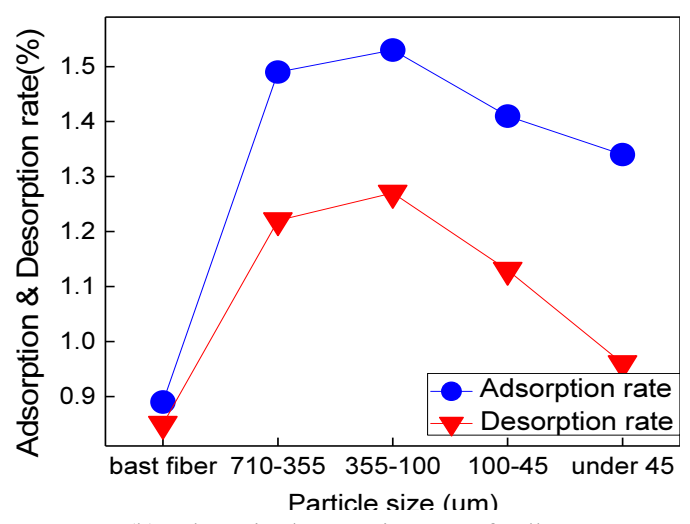

(b) Adsorption/Desorption rate of pellet

Fig. 11. Surface area and adsorption/desorption rate of pellet.

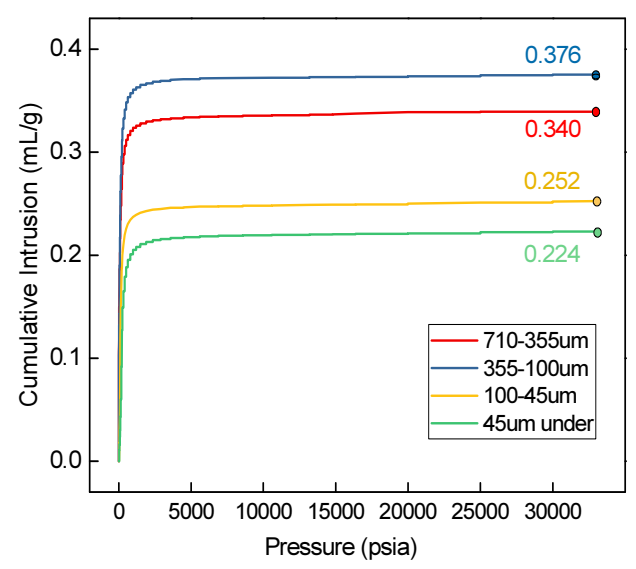

Fig. 12. Cumulative intrusion according to pressure.

기가 작아질수록 흡·방습율이 점차 감소하는 경향을 나 타내었다. 하지만 355-100 $\mathrm{mm}$ 에서 가장 높은 흡. 방습율 값을 확인 할 수 있었으며, 이는 Fig. 12와 Table 3에서 확 인된 펠렛 기공률과 동일한 경향이었다(Fig. 12 및 Table 3 은 수은압입법에 의해 측정된 수은압입 부피와 기공률 값). 각각의 기공률은 $355-100 \mu \mathrm{m}, 710-355 \mu \mathrm{m}, 100-45 \mu \mathrm{m}$, $45 \mu \mathrm{m}$ 미만 순으로 감소하였으며, 흡. 방습율 또한 동일한 순서로 감소하였다. 이는 Fig. 8의 (e), (f), (g) 및 (h)에서 관찰된 펠렛별 기공량의 분포정도와도 유사한 경향인 것 으로 판단되었다. 따라서 기공률과 흡·방습율은 매우 밀
접한 상관성을 갖는 것으로 판단되었다.

Fig. 13은 펠렛별 기공분포를 나타낸 그래프이다. (a) 와 (b)에서는 거대 기공 $(10 \mu \mathrm{m}$ 이상)이 존재하였으며, (c)와 (d)에서는 $10 \mu \mathrm{m}$ 이하의 기공만 확인되었다. 이 중 비교적 우수한 흡·방습 성능을 나타낸 것은 (a) 및 (b)로 기공 크 기도 펠렛의 흡·방습에 긍정적인 영향을 미친 것으로 사 료되었다. (b)의 흡. 방습 성능이 (a)에 비해 우수한 이유 는 거대 기공의 분포는 유사하였으나, 약 $3 \mu \mathrm{m}$ 구간의 기공 분포가 (b)에서 더 높게 나타났기 때문으로 추정되었다.

본 연구에서 제조한 펠렛의 흡. 방습 결과를 $1 \mathrm{~m}^{2}$ 당 흡. 방습량 $\left(\mathrm{g} / \mathrm{m}^{2}\right)$ 으로 환산하여 Fig. 14에 나타내었다. 710$355 \mu \mathrm{m}, 355-100 \mu \mathrm{m}, 100-45 \mu \mathrm{m}$ 및 $45 \mu \mathrm{m}$ 미만의 순으로 $141.1 \mathrm{~g} / \mathrm{m}^{2}, 147.1 \mathrm{~g} / \mathrm{m}^{2}, 135.7 \mathrm{~g} / \mathrm{m}^{2}$ 및 $129 \mathrm{~g} / \mathrm{m}^{2}$ 의 흡습 성 능을, $117.2 \mathrm{~g} / \mathrm{m}^{2}, 123.6 \mathrm{~g} / \mathrm{m}^{2}, 110.2 \mathrm{~g} / \mathrm{m}^{2}$ 및 $93.3 \mathrm{~g} / \mathrm{m}^{2}$ 의 방습 성능이 도출되었다. 국내 청정건강주택 건설기준에 서는 흡. 방습량 $70 \mathrm{~g} / \mathrm{m}^{2}$ 이상은 우수, $50 \mathrm{~g} / \mathrm{m}^{2}$ 이상은 양호 등급으로 명시하고 있다 ${ }^{12)}$. 이에 따라 폐닥나무를 이용한 펠렛의 흡·방습 성능 또한 우수하다고 판단되었으며, 폐 닥나무 가공을 통한 흡·방습 제품으로의 적용 가능성을 기대할 수 있다고 사료되었다. 또한 폐닥나무 가공 과정 에서 인피섬유 내부 기공의 손상을 최소화하고, 입도 제 어가 가능한 방법을 더욱 최적화할 경우에는 좀 더 우수한 흡·방습 특성이 발현될 것으로 사료되었다.

Table 3. Porosity of pellet according to particle size

\begin{tabular}{|c|c|c|c|c|}
\hline Particle size $(\mu \mathrm{m})$ & $710-355$ & $355-100$ & $100-45$ & under 45 \\
\hline Porosity $(\%)$ & 30.7 & 32.9 & 23.0 & 22.1 \\
\hline
\end{tabular}




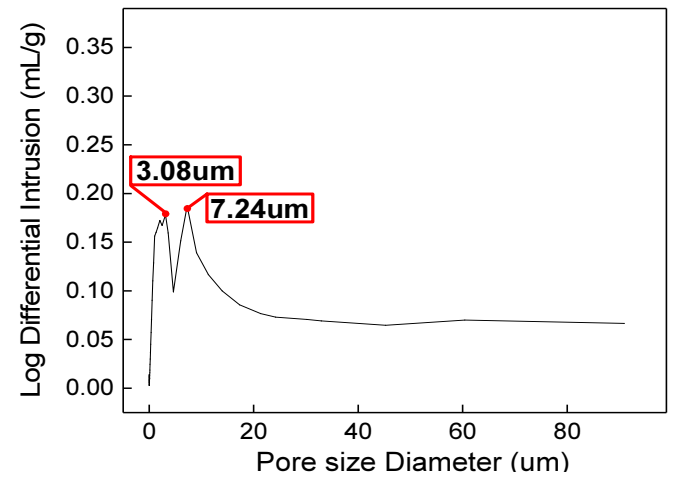

(a) $710-355 \mu \mathrm{m}$

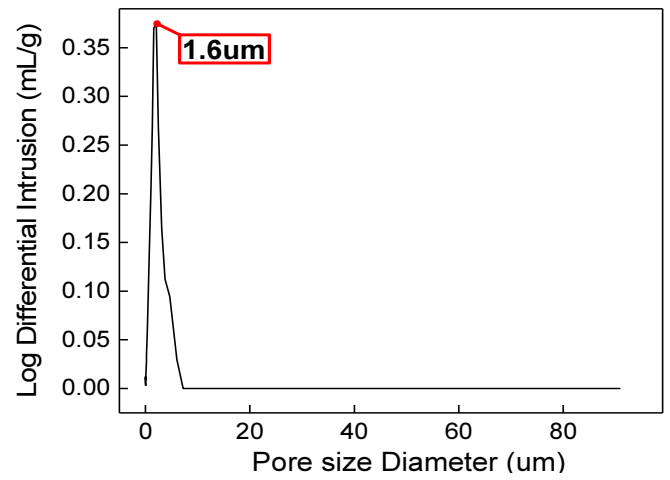

(c) $100-45 \mu \mathrm{m}$

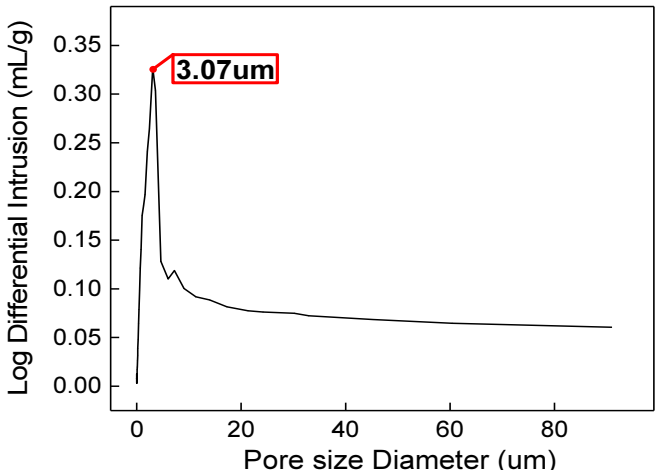

(b) $355-100 \mu \mathrm{m}$

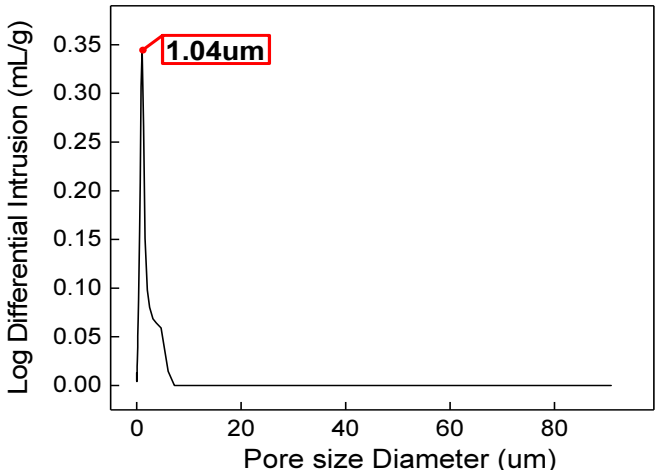

(d) $45 \mu \mathrm{m}$ under

Fig. 13. Pore distribution of pellet according to particle size.

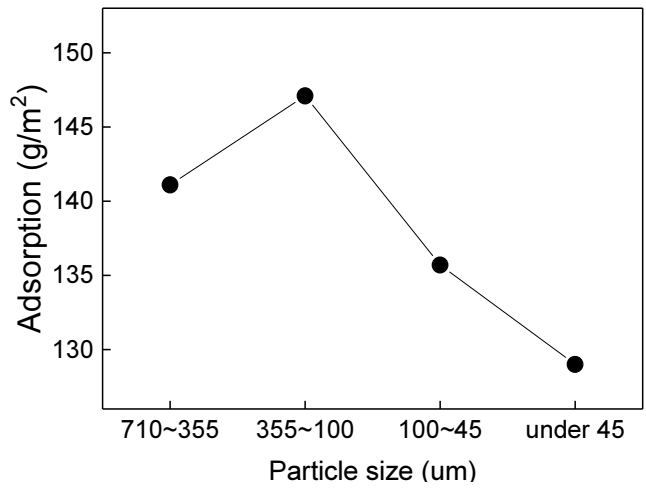

(a) Adsorption performance

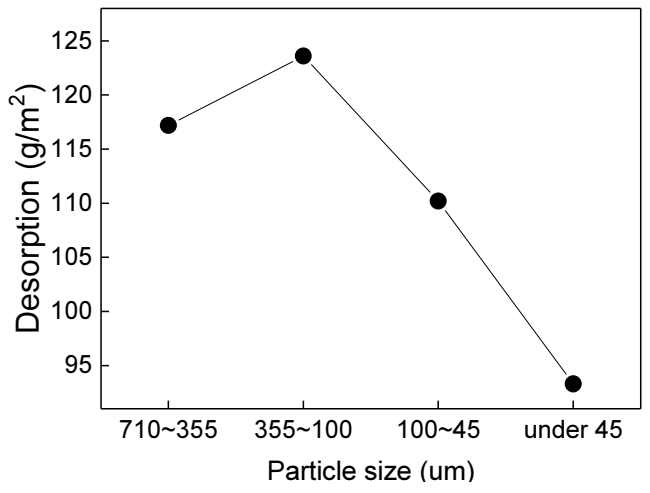

(b) Desorption performance

Fig. 14. Adsorption and Desorption weight per $\mathrm{m}^{2}$.

\section{4. 결 론}

본 연구에서는 폐닥나무를 분쇄하여 조습 제품에 적 용하기 위한 기초연구를 수행하였다. 이를 위해 폐닥나 무 인피섬유와 인피섬유 분쇄 후 입도별로 제조된 펠렛
의 흡. 방습 특성을 분석하였으며, 다음과 같은 결론을 도출하였다.

1. XRD 분석 데이터 결과 $15^{\circ}$ 및 $22^{\circ}$ 에서 천연셀룰로오 스가 검출되었고, 이를 통해 폐닥나무 섬유는 셀룰로오 
스로 구성된 친환경 재료인 것으로 판단된다. 인피섬유 의 미세구조 관찰 시 조습특성의 주요인자로 알려진 섬 유 내 관 형태의 기공이 발견되었다.

2. 폐닥나무의 입도는 710-355 $\mu \mathrm{m}, 355-100 \mu \mathrm{m}, 100-45 \mu \mathrm{m}$ 및 $45 \mu \mathrm{m}$ 로 제어하였으며, 입자의 크기가 감소할수록 비표면적은 증가하였다. 분말의 크기가 감소할수록 비 표면적이 증가하는 경향과는 달리 355-100 $\mu \mathrm{m}>710$ $355 \mu \mathrm{m}>100-45 \mu \mathrm{m}>45 \mu \mathrm{m}$ 미만 > 인피섬유 순으로 흡. 방습량이 감소하였으며, 펠렛의 기공률과 동일한 경향 을 나타내었다. 또한 펠렛 내 거대 기공과 손상되지 않 은 섬유 내 기공의 분포가 흡. 방습 성능에 영향을 주었 을 것으로 판단되었다.

3. $710-355 \mu \mathrm{m}$ 및 $355-100 \mu \mathrm{m}$ 분말은 비교적 온전한 섬유 다발 및 섬유가 산발적으로 펼쳐진 다발로 구성되어 기 공 형성이 용이했을 것으로 추정되며, $100-45 \mu \mathrm{m}$ 및 45 $\mu \mathrm{m}$ 미만은 분쇄 시 생성된 미세입자의 기공 내 침투 및 판상형 입자 적층이 기공 형성에 방해요인으로 작용한 것으로 판단되었다.

4. $1 \mathrm{~m}^{2}$ 당 흡 - 방습량 환산값은 $(710-355 \mu \mathrm{m}, 355-100 \mu \mathrm{m}$, $100-45 \mu \mathrm{m}$ 및 $45 \mu \mathrm{m}$ 미만의 순) 흡습량이 $141.1 \mathrm{~g} / \mathrm{m}^{2}$, $147.1 \mathrm{~g} / \mathrm{m}^{2}, 135.7 \mathrm{~g} / \mathrm{m}^{2}$ 및 $129 \mathrm{~g} / \mathrm{m}^{2}$, 방습량은 117.2 $\mathrm{g} / \mathrm{m}^{2}, 123.6 \mathrm{~g} / \mathrm{m}^{2}, 110.2 \mathrm{~g} / \mathrm{m}^{2}$ 및 $93.3 \mathrm{~g} / \mathrm{m}^{2}$ 수준으로 발 현되었다. 이들 값은 기존 건강주택 기준 값을 충분히 만족하는 수준이며, 향후 입도 제어 등이 더욱 최적화 될 경우에는 좀 더 우수한 흡·방습 특성이 발현될 것 으로 사료되었다.

\section{References}

1. Hye-jin Hwang, Dong-Kwon Kim, Jae-sik Jeong, et al., 2015 : Moisture adsortion and desorption property of the wallpaper using natural substance, Textile Coloration and Finishing, 27(3), pp.210-218.

2. Sang-Jin Lee, Jin-Kyeong Sung, Soon-Ho Kim, et al., 2005 : A study on the properties and fabrications of ecoceramics paint, Journal of the Korean Ceramic Society, 42(10), pp.678-684.

3. Yong Sik Chu, Choon Woo Kwon, Hoon Song, et al., 2008 : Hygroscopic characteristic of hydrothermal reacted panels using porous materials, Journal of the Korean Ceramic Society, 45(12), pp.832-838.

4. Jong-Kyu Lee and Tae-Yeon Kim, 2018 : Evaluation of humidity control ceramic board using gypsum binder, Korean Journal of Materials Research, 28(1), pp.62-67.

5. Dinh-Hieu Vu, Kuen-Sheng Wang, Bui Hoang Bac, 2011 : Humidity control porous ceramics prepared from waste and porous materials, Materials Letters, 65(6), pp.940-943.

6. Jin-Suk Yang, Chung-Heop Kwak, Tae-Soo Suh, et al., 2000 : Preparation and characterization of the humidity self-control materials, Journal of industrial and Engineering Chemistry, 11(8), pp.944-951.

7. J. S. Cha, S. I. Choi, 2016 : KR, 10-2016-0078707.

8. Kun-Young Jang, Dong-Woo Ryu, 2018 : Performance evaluation of water vapour adsorption \& desorption properties of ceramic panel and painting materials for humidity control, Journal of the Architectural Institute of Korea Structure \& Construction, 34(3), pp.43-52.

9. Jae-Jun Park, Kyoung-Hwa Choi, Byoung-Uk Cho, 2017 : Evaluation of low-temperature cooking of paper-mulberry bast fiber with potassium based cooking chemicals, Journal of Korea Technical Association of the Pulp and Paper Industry, 49(3), pp.35-40.

10. Ji Young Lee, Hae Min Jo, Kyoung Min Kim, et al., 2019 : Fundamental study on the cellulose nanofibril manufacture from paper-mulberry fiber, Journal of Korea TAPPI, 51(3), pp.45-51.

11. In-Hee Go, Seon-Hwa Jeong, 2018 : Anatomical, morphological, and chemical characteristics of paper-mulberry wood and bast fiber for raw material of Korean paper (Hanji), Journal of Conservation Science, 34(6), pp.517-524.

12. Ministry of Land, Infrastructure and Transport, Clean Healty Home Construction Standard, http://law.go.kr/adm RulInfoP.do?admRulSeq=2000000054393, January 21. 2020.

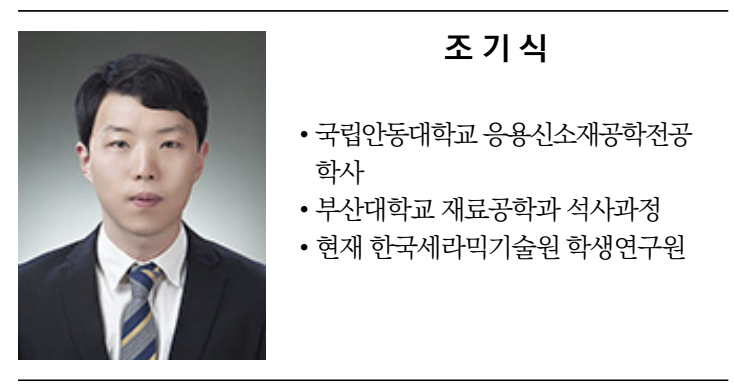




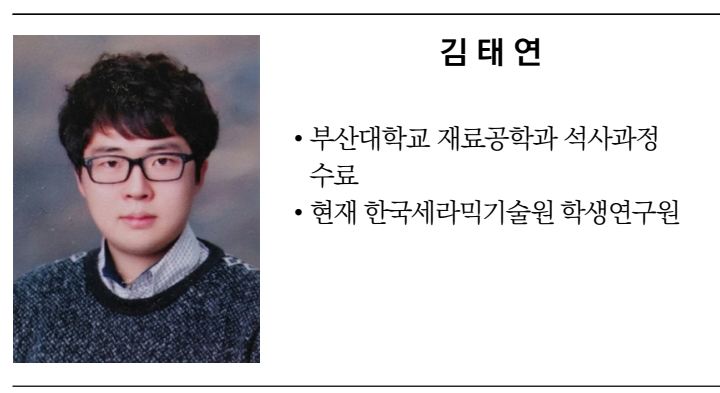

\section{이 오 규}

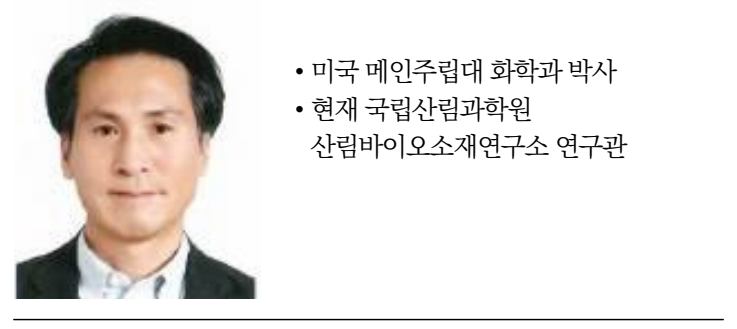

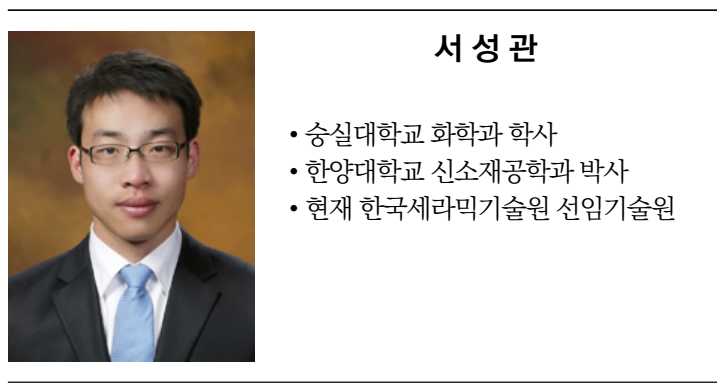

\section{추 용 식}

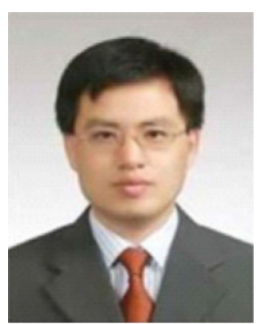

- 한양대학교 신소재공학과 박사

- 라파즈한라시멘트 기술연구소

주임연구원

• 현재 한국세라믹기술원 수석연구원 